\title{
The mechanism of pathological changes of intraventricular hemorrhage in dogs
}

\author{
Jiong Dai, Shanquan Li, Xiaoxiong Li, Wenhao Xiong, Yongming Qiu \\ Department of Neurosurgery, Renji Hospital, Shanghai, China
}

\begin{abstract}
Background: Intraventricular hemorrhage (IVH) is an independent risk factor for both morbidity and mortality in patients with intracerebral hemorrhage and subarchnoid hemorrhage. The pathophysiological mechanisms by which blood within the ventricles causes brain damage are still poorly understood. Settings and Design: We developed a canine (dog) model with long-term survival. Aims: To study the mechanisms of pathological changes associated with IVH. Materials and Methods: The neurological status, cranial computed tomographic findings, and the pathological changes were studied in the dogs with IVH and also in the control dogs, intraventiricular saline injection. Results: In all the dogs in the control group there were no abnormalities in all the three parameters studied. The dogs in the IVH group developed neurological deficits after the blood injection. There was linear relationship between the ventricular volume and blood clot volume in the first week. After the first week, there was progressive enlargement of the ventricular volume, while the clots continued to shrink. There was complete lysis of the clots within 4 weeks. Pathological studies showed distruction of the ependymal lining of the ventricular system, subependymal gliosis and ischemia of the neurons in the subependymal areas, prominently around the aqueduct. Conclusion: Ventricular dilation was the prominent feature following intraventricular injection of the blood. The other pathological features included disruption of ependymal lining, subependymal gliosis, and ischemic necrosis of neurons in the periventricular tissue of the third ventricle, aqueduct, and the fourth ventricle. These pathological may have some role in the ventricular dilatation following IVH.
\end{abstract}

Address for correspondence:

Dr. Jiong Dai,

Department of Neurosurgery, Renji

Hospital, Shan Dong Road 145,

Shanghai, 200001 , China.

E-mail: daijiong@126.com

PMID: 19934554

DOI: $10.4103 / 0028-3886.57798$
Key words: Animal model, intraventricular hemorrhage, pathophysiological mechanism

\section{Introduction}

Spontaneous intracerebral hemorrhage (ICH) and aneurysmal subarachnoid hemorrhage (SAH) may be associated intraventricular hemorrhage (IVH) ${ }^{[1]}$ and it is an independent risk factor for both morbidity and mortality. ${ }^{[2-11]}$ In patients with ICH and IVH, $20 \mathrm{ml}$ of blood in the ventricles is a lethal volume. ${ }^{[8]}$ However, the pathophysiological mechanisms by which blood within the ventricles causes brain damage are still poorly understood. Recent studies have demonstrated that accelerated clearance of IVH and rapid normalization of ventricular volume can be achieved by intraventricular administration of the thrombolytic agents, urokinase or recombinant tissue plasminogen activator (rtPA).$^{[12-18]}$ In this study, we developed a canine (dog) model of IVH with long-term survival and elucidated the possible mechanisms leading to brain damage in IVH.

\section{Materials and Methods}

The experimental protocols were in conformity with the national law for the protection of animals.

\section{Animals}

Sixteen adult mongrel dogs of either gender, each weighing 10 to $17 \mathrm{~kg}$, were used for this study. They were randomly allocated to two groups: (1) IVH group-11 
dogs and (2) control group-5 dogs. IVH group received intraventricular blood injection and control group received intraventricular saline injection.

\section{Operative procedure}

Preparation

Animals were fasted for 12 hours pre-operatively. After general anesthesia, with intra-abdominal injection of $2.5 \%$ thiopental sodium in a dosage of $25 \mathrm{mg} / \mathrm{kg}$ and a subcutaneous injection of atropine in a dosage of $0.4 \mathrm{mg}$, the animals were intubated and ventilated with a 5:3 mixture of nitrous oxide and oxygen. Ventilation was adjusted to maintain arterial $\mathrm{CO}_{2}$ pressure between $35 \sim 45 \mathrm{mmHg}$. A femoral arterial cannula was secured to be connected to the multichannel physiological monitor. Arterial blood pressure and blood gas were monitored. The animals were infused with $500 \mathrm{ml}$ of saline, $20 \mathrm{mg}$ of diazepam, and $16 \times 10^{4} \mathrm{U}$ of gentamycin. The dosage of diazepam was no more than $2 \mathrm{mg} / \mathrm{min}$.

Nine milliliters of blood was withdrawn from the femoral arterial catheter and the syringe containing the blood was placed in a metal basin containing warm sterile saline.

\section{Surgical technique}

The head of the dog was fixed on a stereotactic frame with bilateral external auditory metal bars at the zero point. The body of the lateral ventricle was identified by the stereotactic coordinates: Transverse $=8 \mathrm{~mm}$, vertical $=25 \mathrm{~mm}$, and rostral $=20 \mathrm{~mm}$. The puncture depth was regulated to $20 \mathrm{~mm}$ from the outer table of the cranial skull. A ventricular catheter was placed in the right lateral ventricle with the catheter tip lying within the body of the ventricle.

Dogs in the IVH group were injected $9 \mathrm{ml}$ of prepared autologous arterial blood into the right lateral ventricle via the ventricular catheter over a period of 30 minutes. Dogs in the control group received the same volume of sterile saline. Precaution was taken during the procedure not to inject air. The vital signs, eyelash reaction, and pupil reaction were monitored for any herniation signs in all the dogs. Following the procedure, the dogs were awaken from anesthesia.

\section{Postoperative evaluation}

\section{Neurological status}

The neurological status of all the 16 dogs was evaluated both pre-operatively and daily, post-operatively. We used a four scale system: Grade I = normal; Grade II = drowsy, difficult standing, and reduction in muscle force; Grade III = stupor, slight movement in the limbs, swallowing for liquid; Grade IV = comatose, paralysis, no swallowing movement.

\section{Cranial computed tomographic scans}

Cranial computed tomography (CT) scan was done in all the dogs pre-operatively and at 2 hours, 3 days, 1 week, 2 weeks, 3 weeks, and 4 weeks post-operatively. The dogs were sedated with intra-abdominal injections of $2.5 \%$ thiopental sodium in a dosage of $20 \mathrm{mg} / \mathrm{kg}$ and scanned by Picker scanner (Model 2000, Picker Inc. U.S.A.). Non overlapping contiguous coronal cuts with a constant collimation width of $3 \mathrm{~mm}$ were made to include the entire ventricular system. The image data was fed into a computer with a digital camera (Olympus 2020) and analyzed with SigmaScan Pro Image Analysis Program (Version 5.0.0, SPSS Inc., Chicago, IL) to calculate the ventricular volume and blood clot volume. Because of the artifacts of posterior cranial fossa, the fourth ventricular volume and fourth ventricular blood clot volume could not be measured ideally and were excluded from further analysis.

\section{Pathological studies}

At the end of 4 weeks, all the animals were intubated and anesthetized deeply with intra-abdominal injections of $2.5 \%$ thiopental sodium after confirmation of normal arterial blood gas values. The animals were then sacrificed with intravenous potassium chloride. The brain was fixed by perfusioning $4 \%$ paraformaldehyde through the common carotid arteries. After fixation for a period of 2 hours, the brain was removed intact from the cranium and fixed in $4 \%$ paraformaldehyde solution for 2 weeks. The ependymal and subependymal tissues from the lateral ventricle, the floor of the third ventricle, aqueduct, and the floor of the fourth ventricle were taken for histological examination.

\section{Statistical analysis}

The data were presented as mean \pm SD and one-way ANOVA and linear regression analysis were done. A value of $P<0.05$ was considered statistically significant. All data were analyzed with SPSS, version 13 for windows (SPSS Inc., Chicago, IL).

\section{Results}

\section{Neurological status}

All the 16 dogs were neurologically normal (Grade I) preoperatively.

\section{Intraventricular hemorrhage group}

During blood injection, there was a transient and slight increase in blood pressure, but was still within normal range. Eyelash and pupil reaction were present throughout the procedure.

In the dog no. 3 the CT scan done at 2 hours post-operatively showed blood filling the entire third ventricle and the third ventricle was dilated [Figure 1]. The neurologic status in this dog after blood injection 
was Grade IV for 36 hours and then improvement to Grade III. On the third post-operative day, the dog lapsed into coma and died. The data of this dog was excluded from the statistical analysis. However, the brain was fixed and removed for pathological study. The neurologic status of dogs no. 6, 8, and 11 remained in Grade IV for 24 hours post-operatively. The other 7 dogs were well oriented 12 hours after blood injection. All 10 dogs recovered to Grade I within 6 days postoperatively and remained neurologically stable during the 4-week follow-up period. The only neurologic deficit was gait unsteadiness.

\section{Control group}

Six hours after sterile saline injection, all the 5 control dogs recovered from anesthesia to Grade I and were neurologically normal during the 4 -week follow-up period.

\section{Cranial computed tomographic scans}

The CT scans done pre-operatively in all the 16 dogs showed the normal slit-like ventricle. The ventricular volume and blood clot volume were measured preoperatively and at
2 hours, 3 days, 1 week, 2 weeks, 3 weeks, and 4 weeks postoperatively and designated as $\mathrm{VV}_{0^{\prime}} \mathrm{VV}_{2 \mathrm{~h}^{\prime}} \mathrm{VV}_{3 \mathrm{~d}^{\prime}} \mathrm{VV}_{1 \mathrm{w}^{\prime}}$ $\mathrm{VV}_{2 \mathrm{w}^{\prime}}, \mathrm{VV}_{3 \mathrm{w}^{\prime}}, \mathrm{VV}_{4 \mathrm{w}^{\prime}} \mathrm{CV}_{0^{\prime}} \mathrm{CV}_{3 \mathrm{~d}^{\prime}} \mathrm{CV}_{1 \mathrm{w}^{\prime}} \mathrm{CV}_{2 \mathrm{w}^{\prime}} \mathrm{CV}_{3 \mathrm{w}^{\prime}}$ and $\mathrm{CV}_{4 \mathrm{w}^{\prime}}$.

\section{Intraventricular hemorrhage group}

Preoperative ventricular volume $\left(\mathrm{VV}_{0}\right)$ was $0.93 \pm 0.24 \mathrm{ml}$ [Figure 2a]. After blood injection, the initial ventricular blood clot volume $\left(\mathrm{CV}_{0}\right)$ varied from 3.96 to $6.70 \mathrm{ml}$ with a mean of $5.35 \pm 0.90 \mathrm{ml}$ and $\mathrm{VV}_{2 \mathrm{~h}}$ was $5.83 \pm 0.81 \mathrm{ml} . \mathrm{VV}_{3 \mathrm{~d}}$ was $5.32 \pm 0.72 \mathrm{ml}, \mathrm{CV}_{3 \mathrm{~d}}$ was $4.51 \pm 0.89 \mathrm{ml}, \mathrm{VV}_{1 \mathrm{w}}$ was $6.03 \pm 0.76 \mathrm{ml}$, and $\mathrm{CV}_{1 \mathrm{w}}$ was $3.39 \pm 0.87 \mathrm{ml}$ [Figure $2 \mathrm{~b}$ ]. The linear regression value was significant: $\mathrm{VV}_{2 \mathrm{~h}}$ against $\mathrm{CV}_{0}(\mathrm{~b}=0.87, P=0.00001), \mathrm{VV}_{3 \mathrm{~d}}$ against $\mathrm{CV}_{3 \mathrm{~d}}(\mathrm{~b}=0.69$, $P=0.002)$ and $\mathrm{VV}_{1 \mathrm{w}}$ against $\mathrm{CV}_{1 \mathrm{w}}(\mathrm{b}=0.75, P=0.001)$. The ventricular volume contracted as the blood clot volume dissolved in the first week post-operatively [Figure 2c and $2 \mathrm{~d}]$. But after the first week, the ventricular volume progressively increased while the blood clot volume decreased. The blood clots dissolved completely within 4 weeks post-operatively [Figure 2e-g]. Tables 1 and 2 show the details of blood clot volume and ventricular volume in the IVH group [Figure 3].

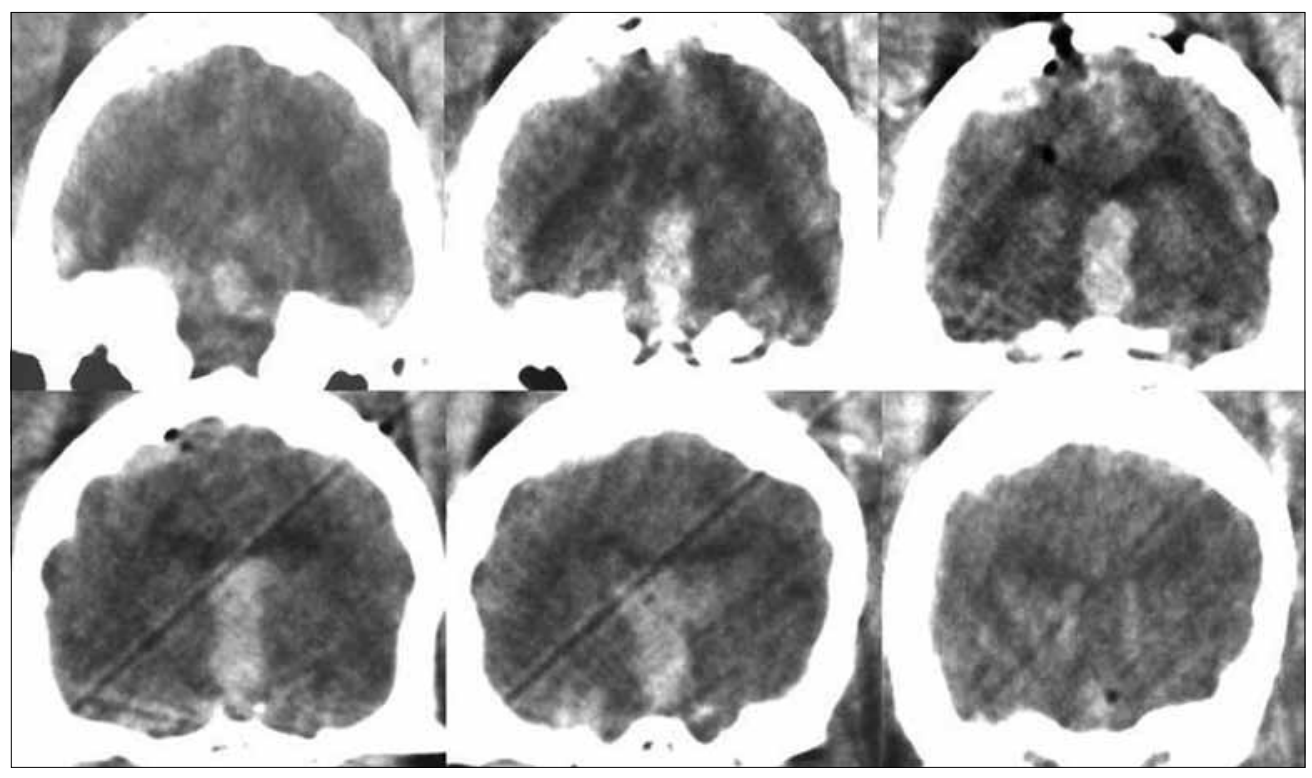

Figure 1: The computed tomographic scan of dog no. 3 in the intraventricular hemorrhage group

\begin{tabular}{|c|c|c|c|c|c|c|}
\hline Dog no. & $\mathrm{CV}_{0}$ & $\mathrm{CV}_{3 \mathrm{~d}}$ & $\mathrm{CV}_{1 \mathrm{w}}$ & $\mathrm{CV}_{2 \mathrm{w}}$ & $\mathrm{CV}_{3 \mathrm{w}}$ & $\mathrm{CV}_{4 \mathrm{w}}$ \\
\hline 1 & 3.96 & 3.10 & 2.02 & 0.33 & 0.00 & 0.00 \\
\hline 2 & 4.43 & 3.58 & 2.39 & 0.47 & 0.00 & 0.00 \\
\hline 4 & 4.89 & 4.03 & 2.78 & 0.92 & 0.00 & 0.00 \\
\hline 5 & 5.45 & 4.59 & 3.63 & 1.82 & 0.40 & 0.00 \\
\hline 6 & 6.61 & 5.75 & 4.59 & 2.54 & 0.63 & 0.00 \\
\hline 7 & 5.14 & 4.28 & 3.41 & 1.20 & 0.52 & 0.00 \\
\hline 8 & 6.70 & 5.84 & 4.61 & 2.51 & 0.92 & 0.00 \\
\hline 9 & 5.97 & 5.11 & 3.96 & 2.12 & 0.77 & 0.00 \\
\hline 10 & 4.76 & 4.04 & 2.89 & 1.55 & 0.48 & 0.00 \\
\hline 11 & 5.63 & 4.77 & 3.62 & 1.80 & 0.39 & 0.00 \\
\hline Mean \pm SD & $5.35 \pm 0.90$ & $4.51 \pm 0.89$ & $3.39 \pm 0.87$ & $1.53 \pm 0.78$ & $0.41 \pm 0.33$ & 0 \\
\hline
\end{tabular}


Based on the early neurologic status at 24 hours the dogs with IV blood injection were grouped into two groups: Group 1 (dog nos. 6,8, and 11) and Group 2: (all other 7 dogs). The $\mathrm{CV}_{0}$ for Group 1 and Group 2 were $6.31 \pm 0.59 \mathrm{ml}$ and $4.94 \pm 0.66 \mathrm{ml}$, respectively and the corresponding $\mathrm{VV}_{2 \mathrm{~h}}$ were $6.63 \pm 0.43 \mathrm{ml}$ and

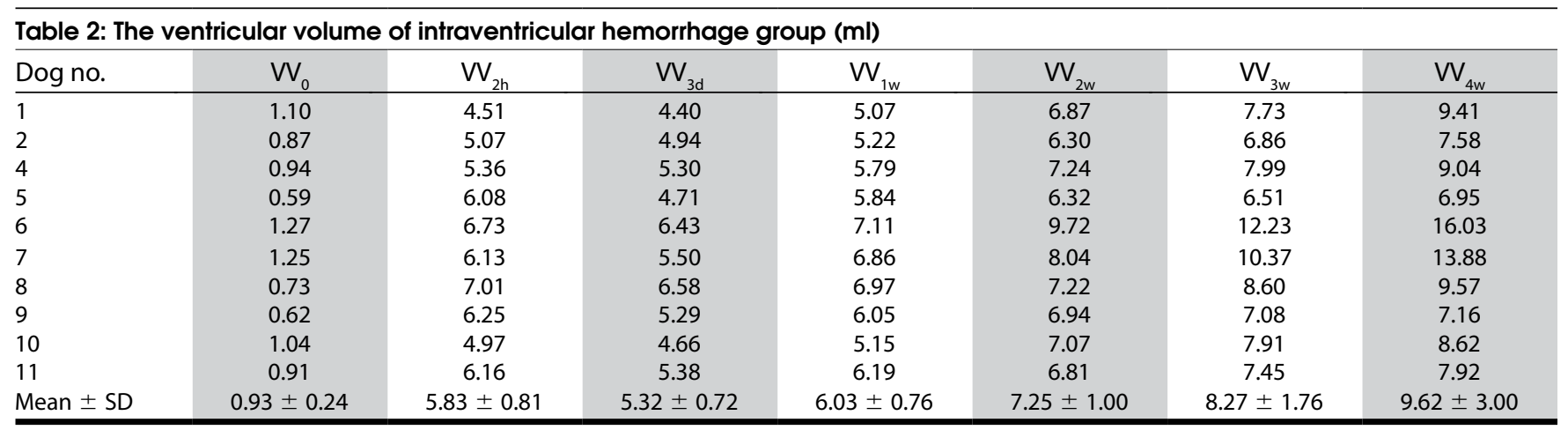

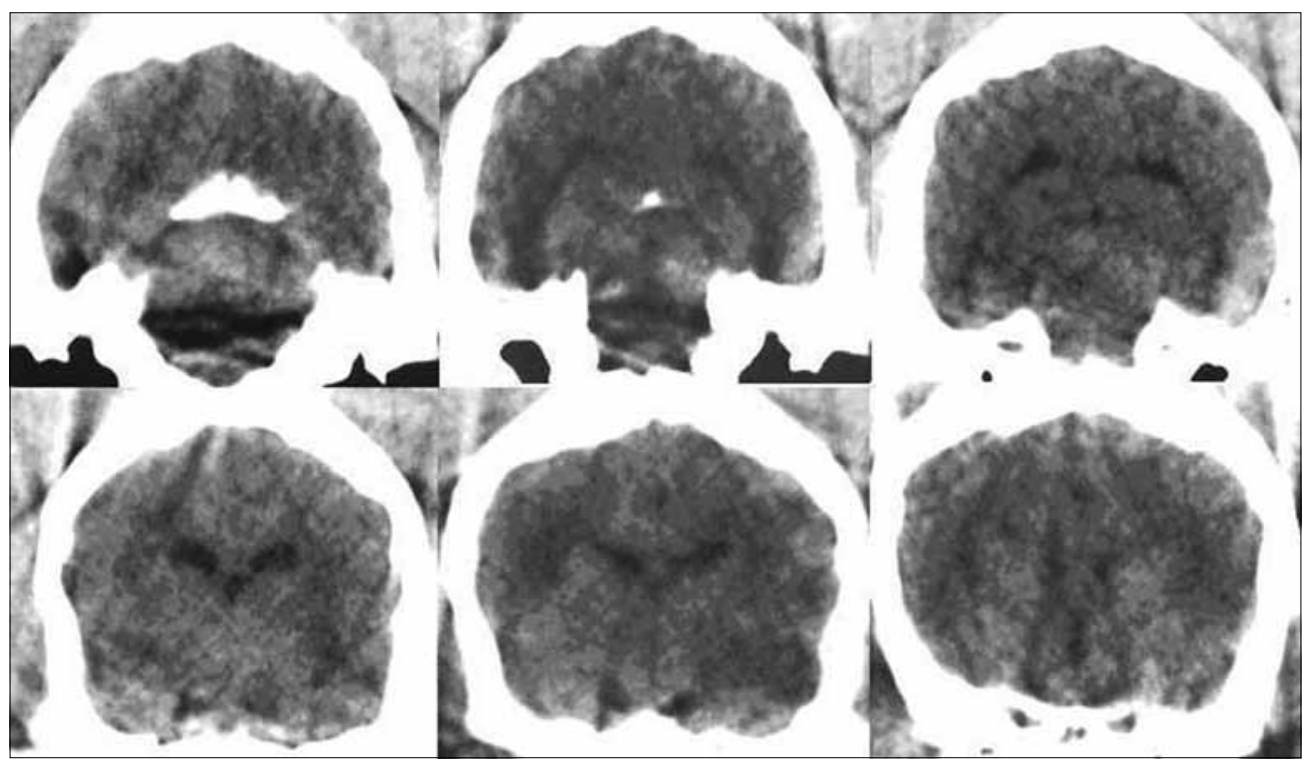

Figure 2a: The serial computed tomographic scans of an intraventricular hemorrhage model - Preoperative

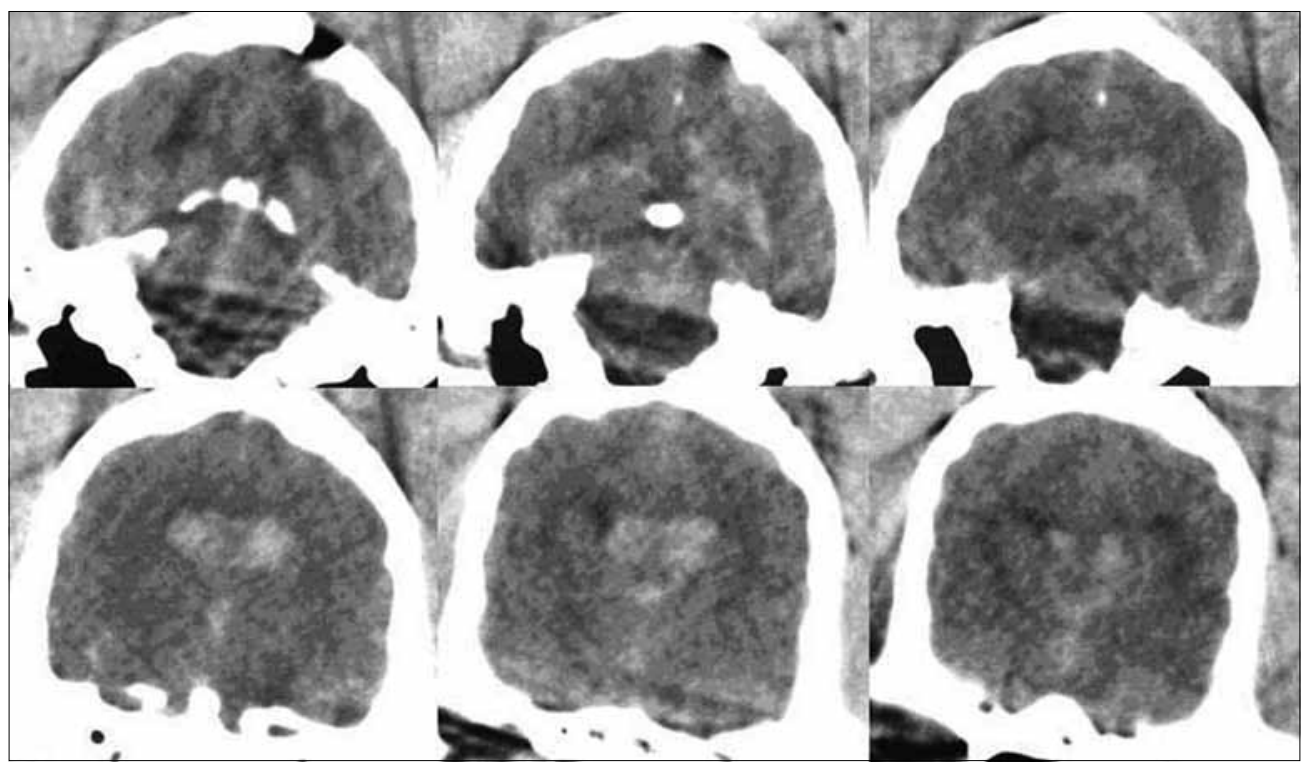

Figure 2b: The serial computed tomographic scans of an intraventricular hemorrhage model $-\mathbf{2}$ hours postoperatively 


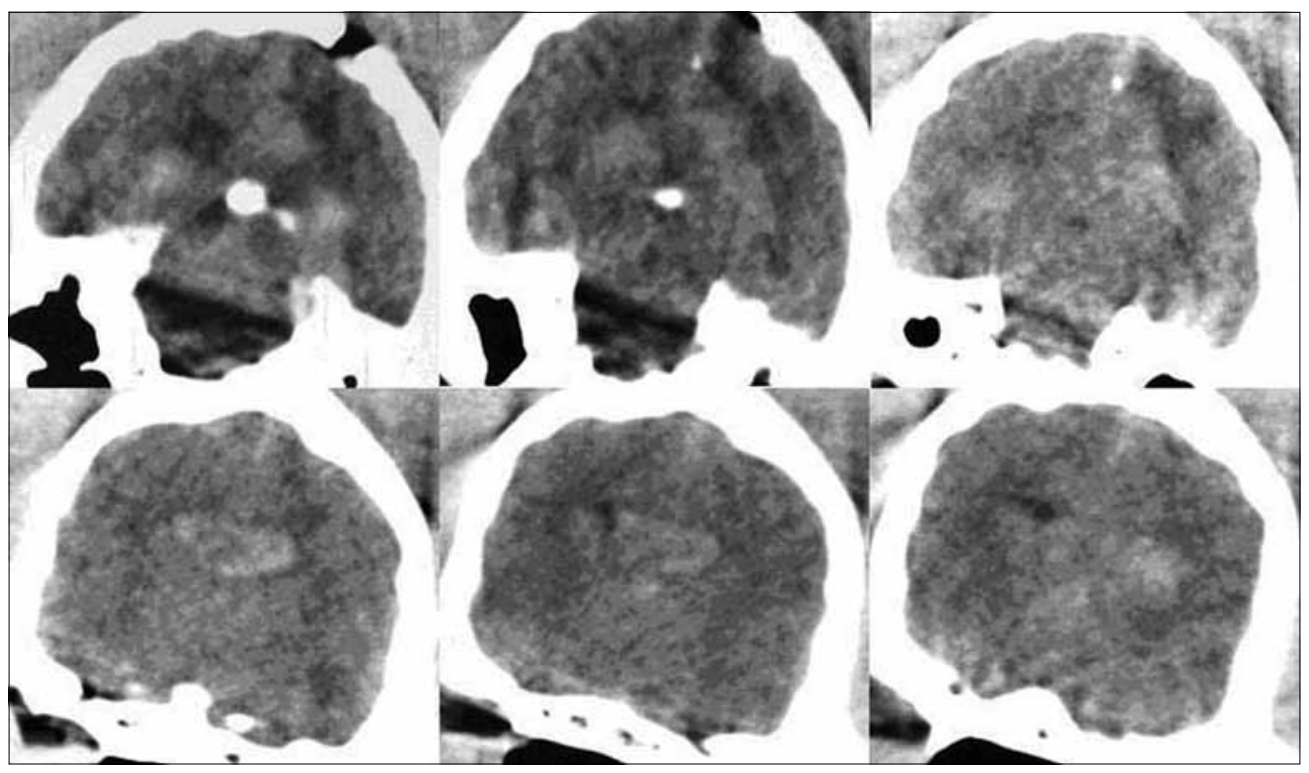

Figure 2c: The serial computed tomographic scans of an intraventricular hemorrhage model -3 days postoperatively

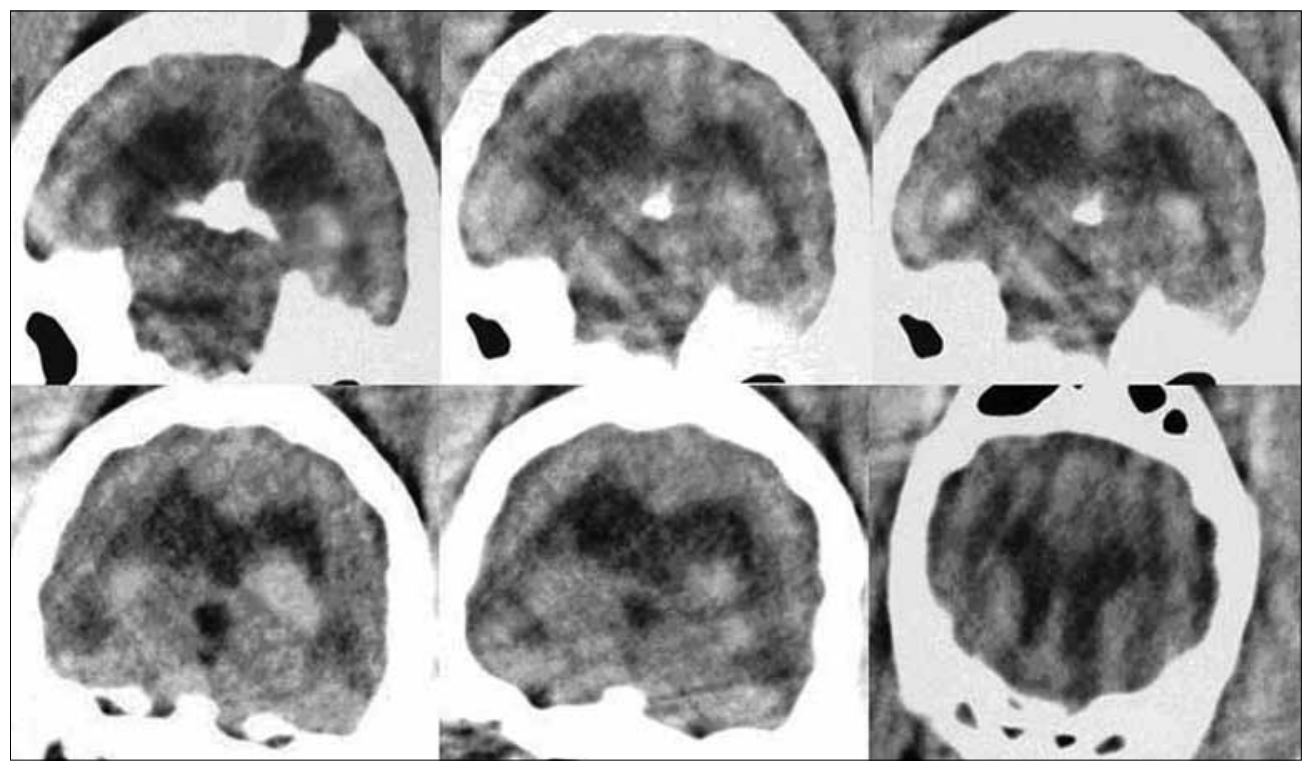

Figure 2d: The serial computed tomographic scans of an intraventricular hemorrhage model - 1 week postoperatively

$5.48 \pm 0.68 \mathrm{ml}$, respectively. Comparisons of $\mathrm{CV}_{0}$ and $\mathrm{VV}_{2 \mathrm{~h}}$ between the two groups showed statistically significant differences $\left(\mathrm{P}_{\mathrm{CV} 0}=0.015\right.$ and $\left.\mathrm{P}_{\mathrm{vV} 2 \mathrm{~h}}=0.028\right)$, implying that the initial blood clot volume in the ventricles was one of the main factors impacting the early neurological status. $\mathrm{VV}_{4 \mathrm{w}} / \mathrm{VV}_{0}$, which represented the degree of ventricular dilatation, was $10.40 \pm 1.83$. The linear regression of $\mathrm{VV}_{4 \mathrm{w}} / \mathrm{VV}_{0}$ against $\mathrm{CV}_{0}$ was significant $(b=1.71, P=0.002)$.

\section{Control group}

The ventricular volume of all 5 dogs in the control group remained normal after sterile saline injection for the 4-week follow-up period. Table 3 shows the details of the ventricular volume in the control group [Figure 4]

\section{Pathological studies}

Intraventricular hemorrhage group

No blood clot was found in the ventricles of all $10 \mathrm{dogs}$ brains in the IVH group. The space between the ependymal cells of the ependymal lining of the lateral ventricle, the floor of the third ventricle, the aqueduct, and the floor of the fourth ventricle was enlarged. There was a patchy loss of ependymal cells in some areas and slight subependymal gial proliferation in areas of maximal ependymal loss. There were ischemic neurons in the subependymal tissues of the floor of the third ventricle, aqueduct, and the floor of the fourth ventricle. 


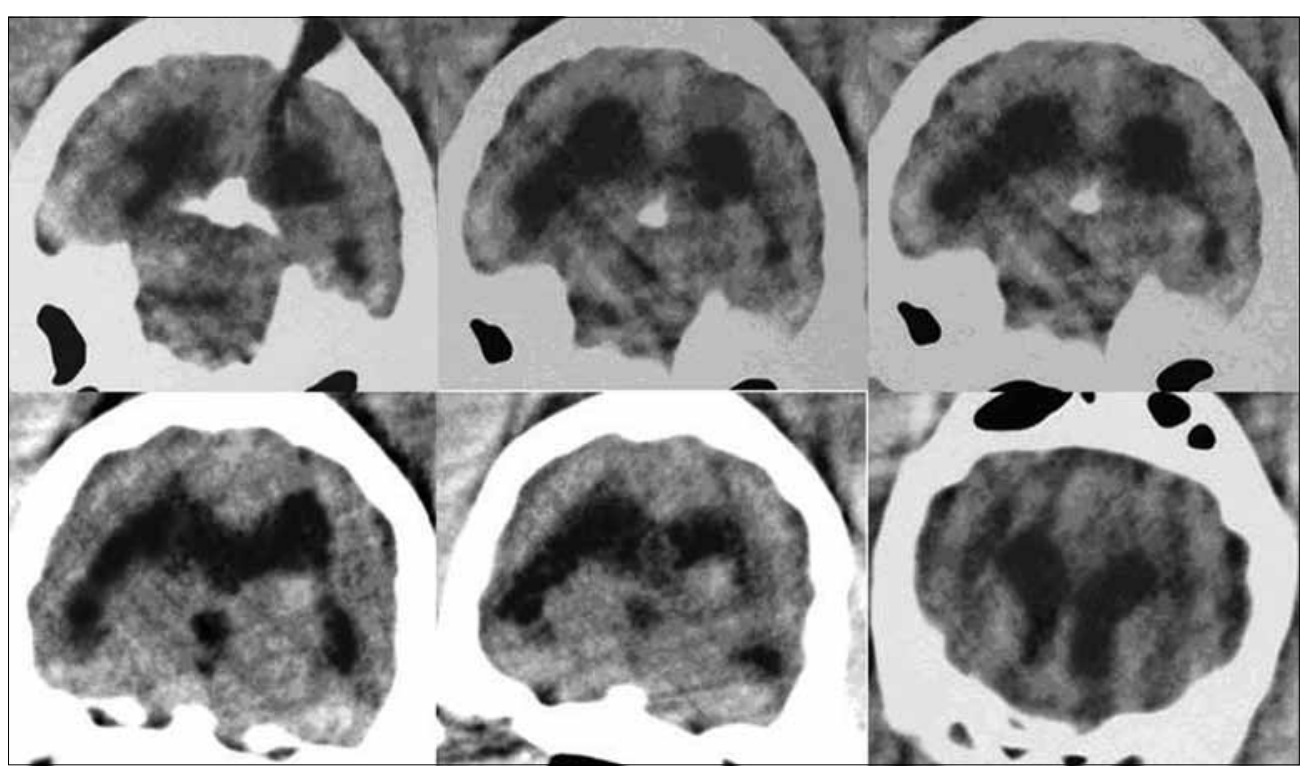

Figure 2e: The serial computed tomographic scans of an intraventricular hemorrhage model - 2 weeks postoperatively

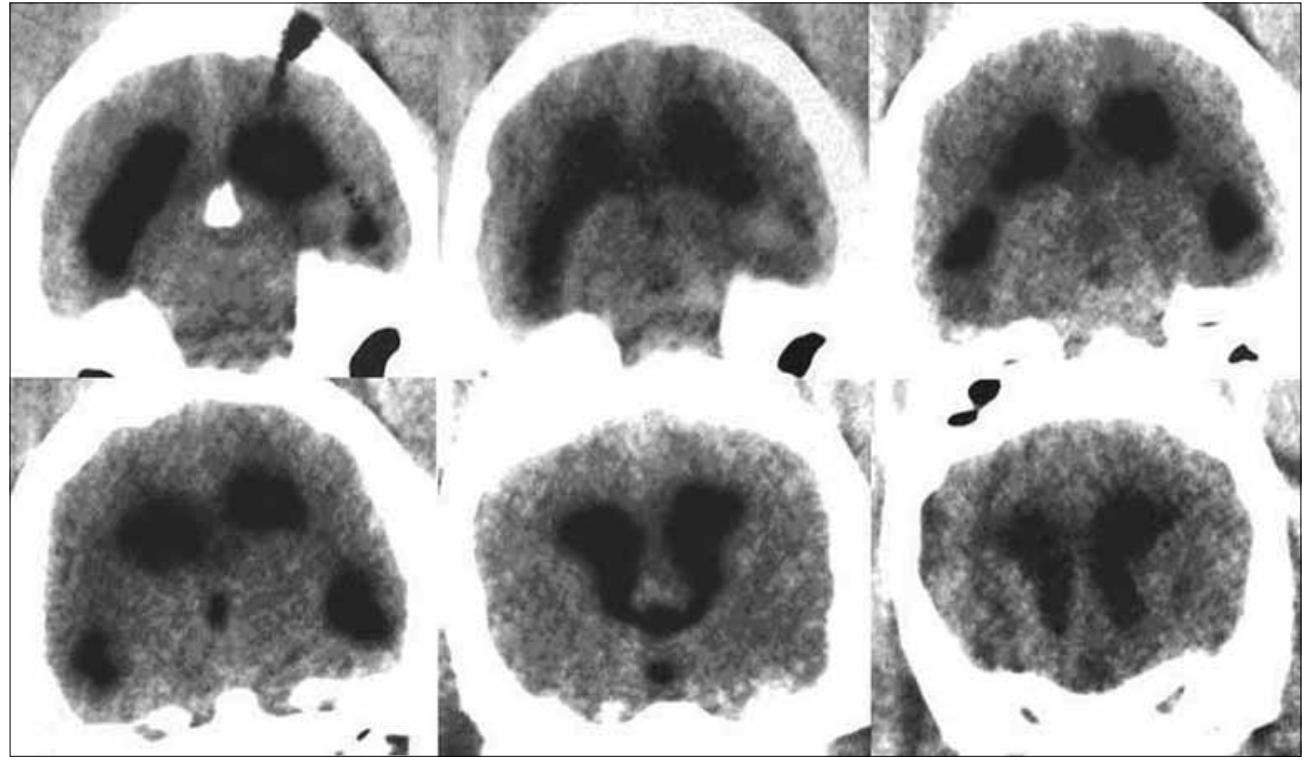

Figure 2f: The serial computed tomographic scans of an intraventricular hemorrhage model -3 weeks postoperatively

These cells were triangular in shape. Their cytoplasma was easonophilic, and their nuclei disappeared. These pathological changes were most prominent in the tissues surrounding the aqueduct [Figure 5]. Ischemic neurons were more in the subependymal tissues of the third ventricle and aqueduct in the Dog no. 3, whose CT scan done 2 hours post-operatively showed casting of the third ventricle with blood clots [Figure 6].

\section{Control group}

In the control group, the ependymal lining and subependymal tissue of the lateral ventricle, the floor of the third ventricle, aqueduct, and the floor of the fourth ventricle were normal [Figure 7].

\section{Discussion}

Ventricular dilation following IVH is a common complication and is associated with poor outcomes. ${ }^{[19,20]}$ The outcomes are much worse when the third and/or fourth ventricle are dilated and casted with blood. ${ }^{[13,20]}$ Clinical and experimental studies suggest that the ventricular dilatation following IVH may be due to 1) the impaired CSF circulation and absorption and 2) the mass effect of blood clot on the ventricular wall.. ${ }^{[11,19-21]}$

An effective IVH animal model would be extremely useful to study the pathophysiology of IVH and also for testing new treatment strategies. Only a very few 


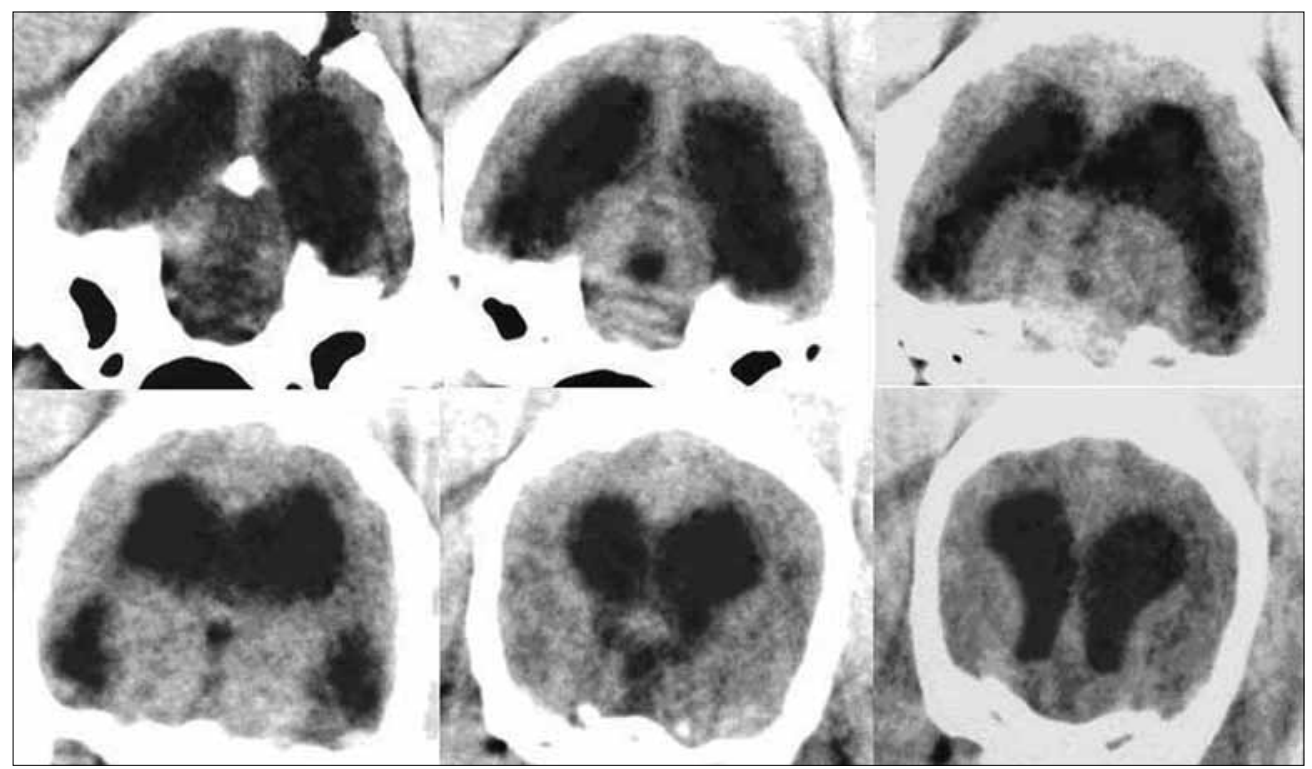

Figure 2g: The serial computed tomographic scans of an intraventricular hemorrhage model - 4 weeks postoperatively

\begin{tabular}{lccccccc}
\hline \multicolumn{7}{l}{ Table 3: The ventricular volume of control group (ml) } \\
\hline Dog no. & $\mathrm{VV}_{0}$ & $\mathrm{VV}_{2 \mathrm{~h}}$ & $\mathrm{VV}_{3 \mathrm{~d}}$ & $\mathrm{VV}_{1 \mathrm{w}}$ & $\mathrm{VV}_{2 \mathrm{w}}$ & $\mathrm{VV}_{3 \mathrm{w}}$ & $\mathrm{VV}_{4 \mathrm{w}}$ \\
\hline 1 & 1.07 & 1.09 & 1.08 & 1.07 & 1.06 & 1.05 & 1.09 \\
2 & 0.85 & 0.83 & 0.88 & 0.86 & 0.85 & 0.82 & 0.84 \\
3 & 1.03 & 1.01 & 1.05 & 1.02 & 1.03 & 0.99 & 0.78 \\
4 & 0.79 & 0.82 & 0.78 & 0.79 & 0.8 & 0.81 & 0.99 \\
5 & 0.98 & 1.01 & 1 & 0.99 & 0.97 & 0.97 \\
Mean $\pm \mathrm{SD}$ & $0.94 \pm 0.12$ & $0.95 \pm 0.12$ & $0.96 \pm 0.13$ & $0.95 \pm 0.12$ & $0.94 \pm 0.11$ & $0.93 \pm 0.12$ & $0.94 \pm 0.12$ \\
\hline
\end{tabular}

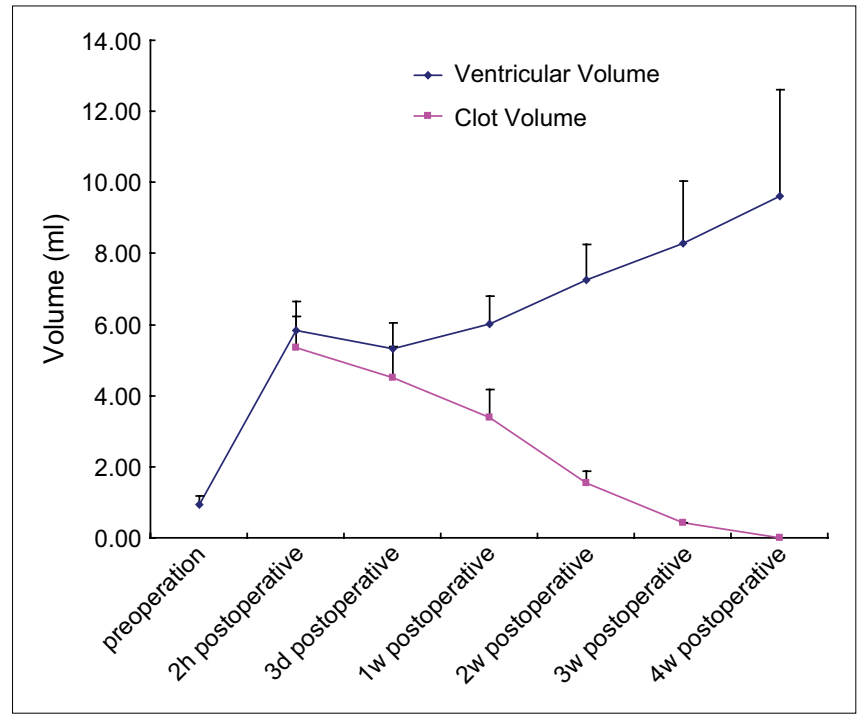

Figure 3: The dynamic changes of ventricular volume and blood clot volume of the intraventricular hemorrhage group

experimental models of IVH have been developed. Pang, et al., ${ }^{[22]}$ developed an IVH model in dogs by intraventricular injection of $9 \mathrm{ml}$ of solid autologous blood and in this model it took 38 to 65 days for complete lysis of blood in the ventricles. An IVH model in pigs was developed by intraventricular injection of $10 \mathrm{ml}$ of

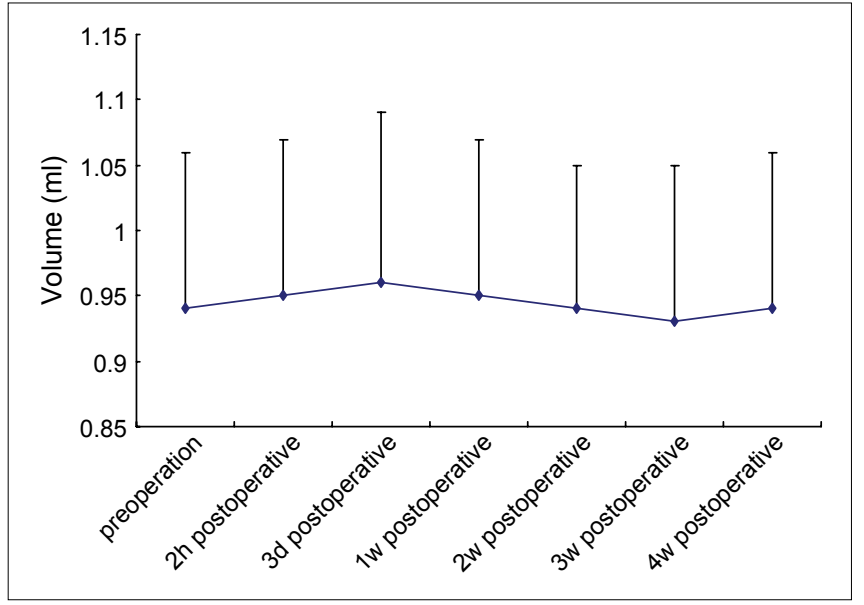

Figure 4: The changes of ventricular volume in the control group

blood mixed with thrombin. In this model the ventricular volume returned to normal values within 6 weeks by complete clot resolution. ${ }^{[11]}$ Lodhia, et al. ${ }^{[23]}$ developed an adult rat model of IVH by injecting $0.2 \mathrm{ml}$ of arterial blood into the lateral ventricle. There was almost complete clot resolution within one week. In humans follow-up CT studies have shown that it takes three weeks for the resolution of intraventricular hemorrhage 

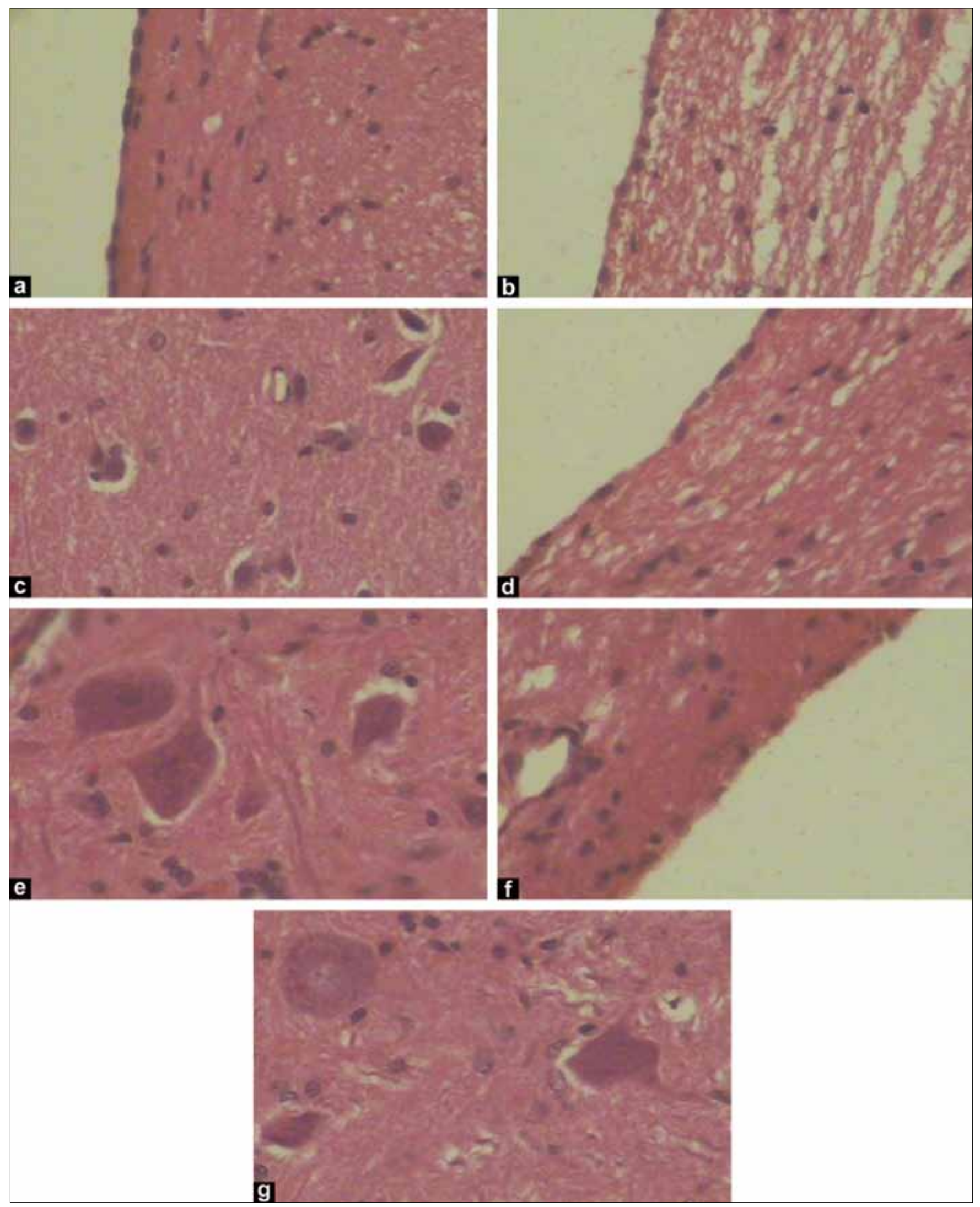

Figure 5: The pathological changes in the intraventricular hemorrhage group (leica DM5000B, $\times 200$ ) The space between ependymal cells of the ependymal lining of the lateral ventricle (a), the floor of the third ventricle (b), Sylvian aqueduct (d), and the floor of the fourth ventricle (f) had enlarged. There was patchy loss of ependymal cells in some areas and slight subependymal gial proliferation subjacent to areas of maximal ependymal loss. Some acidophil necrotic neurons were found in the subependymal tissues of the floor of the third ventricle (c), Sylvian aqueduct (e), and the floor of the fourth ventricle (g) 


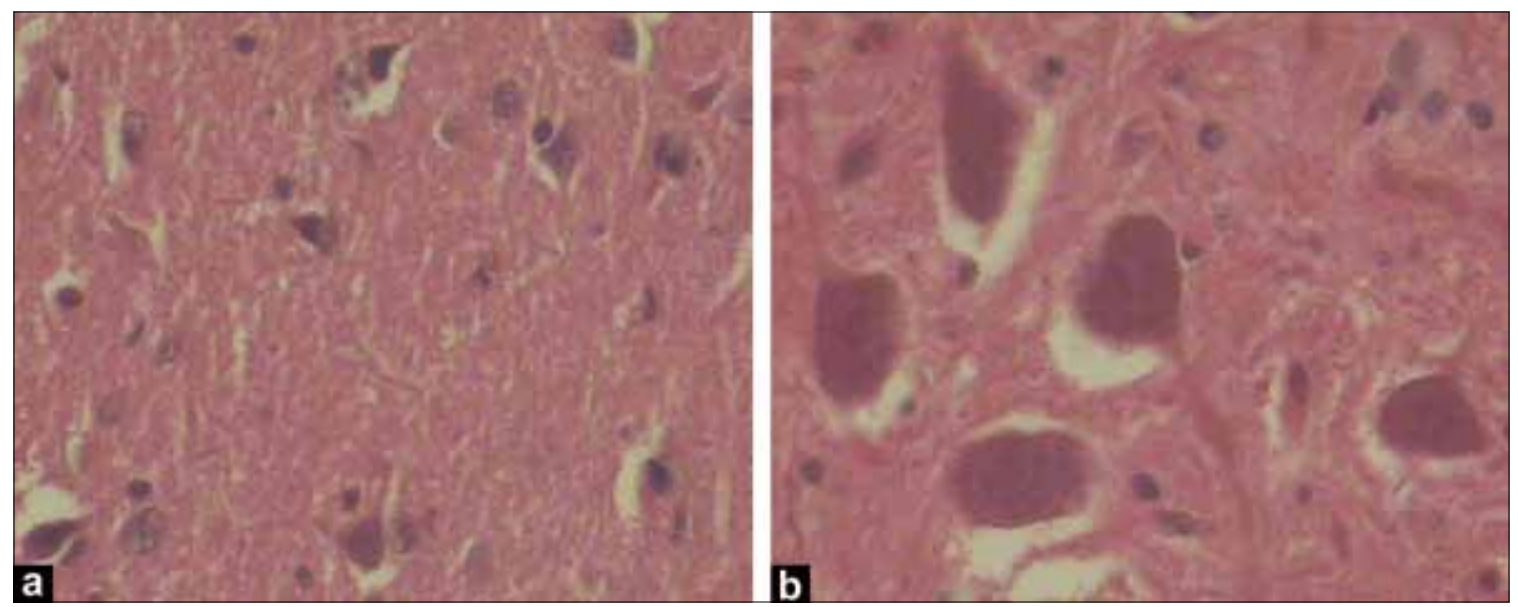

Figure 6: The pathological changes in the subependymal tissues of the third ventricle (a) and sylvian aqueduct (b) of dog no. 3 in the intraventricular hemorrhage group (leica DM5000B, ×200)
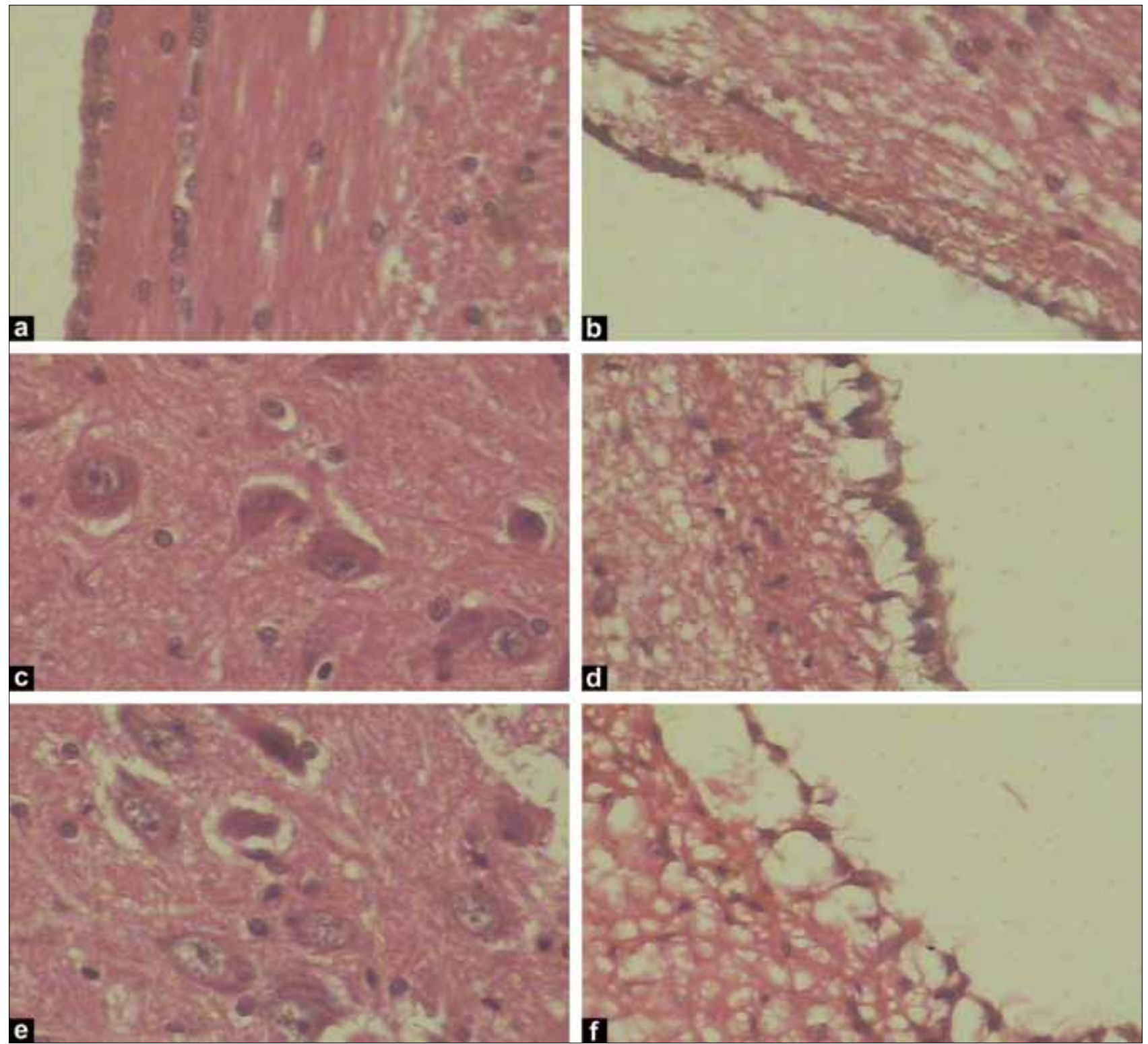

Figure 7: The pathological changes of control group(leica DM5000B, $\times 200)$. The ependymal lining and subependymal tissues of the lateral ventricle $(a)$ the floor of the third ventricle $(b, c)$ sylvian aqueduct $(d, e)$ and the floor of the fourth ventricle $(f, g)$ were normal 


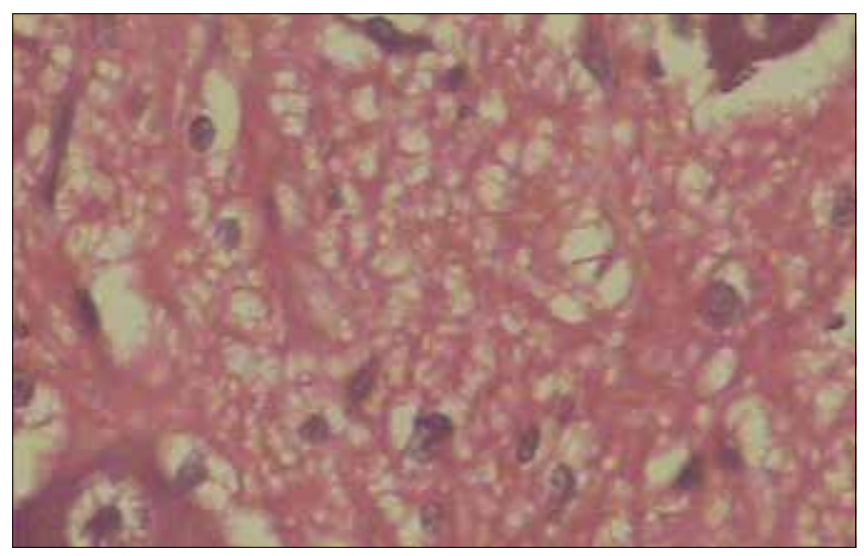

Figure $7 \mathrm{~g}$ : The pathological changes of control group(leica DM5000B, $\times 200$ ). The ependymal lining and subependymal tissues of the lateral ventricle $(a)$ the floor of the third ventricle $(b, c)$ sylvian aqueduct $(d, e)$ and the floor of the fourth ventricle $(f, g)$ were normal

to disappear. ${ }^{[24]}$ In our model intraventricular blood injection was associated with ventricular dilatation and it took four weeks for the blood clot in the ventricles to dissolve completely. Our model closely simulates the situation in human IVH. In our model the initial intraventricular blood clot volume $\left(\mathrm{CV}_{0}\right)$ was $5.35 \pm 0.90 \mathrm{ml}$, much less than the injected $9 \mathrm{ml}$ of blood. The following factors might explain this discrepancy: 1) The volume of blood clot created from $9 \mathrm{ml}$ of whole blood was probably less than $9 \mathrm{ml}, 2$ ) the blood clot in the fourth ventricle was excluded from the measurement of clot volume, and 3) some of the blood clot might have gone into the basal cistern. In the earlier experimental models such phenomenon has been observed. ${ }^{[11,22]}$

Within the first week after blood clot injection, there was linear relationship between the ventricular volume and the blood clot volume. These observations suggest that in the early stages of IVH the ventricular dilatation may be related to the mass effect of blood clot on the ventricular wall. After one week there was progressive increase in the ventricular volume while there was decrease in the volume of the blood clot. Probably the ventricular dilatation at this stage may be due to impaired cerebrospinal fluid circulation and absorption.

In the dogs in the IVH group there was destruction of the ependymal lining of the ventricular system and subependymal glial proliferation. These changes might be the result of the mechanical effect of blood clot distending the ventricular walls and the toxic effect of thrombin to the ependymal cells. ${ }^{[25]}$ These pathological changes may cause reduced compliance of the periventricular tissue and would prevent the periventricular tissues from recoiling, leading to ventricular dilatation. This may be the other mechanism for the progressive ventricular dilatation seen in the the IVH dogs after the first week.
In the dogs in the IVH group there were ischemic changes in the neurons in the periventricular tissues of the third ventricle, aqueduct, and the fourth ventricle. These changes were more pronounced in the periaqueductal tissue. In the Dog no. 3, in whom third ventricle was casted with blood clot and dilated, there were more ischemic neurons in the subependymal tissue of the third ventricle and aqueduct. This dog died early in the course of the experiment. The pathogenesis of ischemic changes in the neurons may be due to: 1) A decrease in cerebral blood flow in the periventricular tissue because of mechanical compression by the ventricular volume on the periventricular perforating vessels, 2) possible reduction in the number of capillaries in the periventricular tissue as a result of ventricular dilatation, ${ }^{[26]} 3$ ) reduced cerebral perfusion pressure due to increased intracranial pressure after IVH and 4) vasospasm rarely associated with IVH. ${ }^{[27-30]}$

\section{References}

1. Graeb DA, Robertson WD, Lapointe JS, Nugent RA, Harrison PB. Computed tomographic diagnosis of intraventricular hemorrhage. Radiology 1982;143:91-6.

2. Bhattathiri PS, Gregson B, Prasad KS, Mendelow AD; STICH Investigators. Intraventricular hemorrhage and hydrocephalus after spontaneous intracerebral hemorrhage: Results from the STICH trial. Acta Neurochir (suppl) 2006;96:65-8.

3. Naff NJ. Intraventricular hemorrhage in adults. Curr Treat Options Neurol 1999;1:173-8.

4. Passero S, Ulivelli M, Reale F. Primary intraventricular hemorrhage in adults. Acta Neurol Scand 2002;105:115-9.

5. Hütter BO, Kreitschmann-Andermahr I, Mayfrank L, Rohde V, Spetzger U, Gilsbach JM. Functional outcome after aneurysmal subarachnoid hemorrhage. Acta Neurochir Suppl 1999;72:157-74.

6. Kassell NF, Torner JC, Haley EC Jr, Jane JA, Adams HP, Kongable GL. The International Cooperative Study on the Timing of Aneurysm Surgery, Part 1: Overall management results. J Neurosurg 1990;73:18-36.

7. Daverat P, Castel JP, Dartigues JF, Orgogozo JM. Death and functional outcome after spontaneous intracerebral hemorrhage: A prospective study of 166 cases using multivariate analysis. Stroke 1991;22:1-6.

8. Young WB, Lee KP, Pessin MS, Kwan ES, Rand WM, Caplan LR. Prognostic significance of ventricular blood in supratentorial hemorrhage: A volumetric study. Neurology 1990;40:616-9.

9. Hallevi H, Albright KC, Aronowski J, Barreto AD, Martin-Schild S, Khaja AM, et al. Intraventricular hemorrhage: Anatomic relationships and clinical implications. Neurology 2008;70:848-52.

10. Mayfrank L, Hütter BO, Kohorst Y, Kreitschmann-Andermahr I, Rohde V, Thron A, et al. Influence of intraventricular hemorrhage on outcome after rupture of intracranial aneurysm. Neurosurg Rev 2001;24:185-91.

11. Mayfrank L, Kissler J, Raoofi R, Delsing P, Weis J, Küker W, et al. Ventricular dilatation in experimental intraventricular hemorrhage in pigs: Characterization of cerebrospinal fluid dynamics and the effects of fibrinolytic treatment. Stroke 1997;28:141-8.

12. Akdemir H, Selçuklu A, Paşaoğlu A, Oktem IS, Kavuncu I. Treatment of intraventricular hemorrhage by intraventricular infusion of urokinase. Neurosurg Rev 1995;18:95-100.

13. Coplin WM, Vinas FC, Agris JM, Buciuc R, Michael DB, Diaz FG, et al. A cohort study of the safety and feasibility of intraventricular urokinase for nonaneurysmal spontaneous intraventricular hemorrhage. Stroke 1998;29:1573-9.

14. Tung MY, Ong PL, Seow WT, Tan KK. A study on the efficacy of intraventricular urokinase in the treatment of intraventricular 
haemorrhage. Br J Neurosurg 1998;12:234-9.

15. Naff NJ, Hanley DF, Keyl PM, Tuhrim S, Kraut M, Bederson J, et al. Intraventricular thrombolysis speeds blood clot resolution: Results of a pilot, prospective, randomized, double-blind, controlled trial. Neurosurgery 2004;54:577-84.

16. Findlay JM, Grace MG, Weir BK. Treatment of intraventricular hemorrhage with tissue plasminogen activator. Neurosurgery 1993;32:941-7.

17. Goh KY, Poon WS. Recombinant tissue plasminogen activator for the treatment of spontaneous adult intraventricular hemorrhage. Surg Neurol 1998;50:526-32.

18. Naff NJ, Carhuapoma JR, Williams MA, Bhardwaj A, Ulatowski JA, Bederson J, et al. Treatment of intraventricular hemorrhage with urokinase: Effects on 30-Day survival. Stroke 2000;31:841-7.

19. Mohr G, Ferguson G, Khan M, Malloy D, Watts R, Benoit B, et al. Intraventricular hemorrhage from ruptured aneurysm: Retrospective analysis of 91 cases. J Neurosurg 1983;58:482-7.

20. Shapiro SA, Campbell RL, Scully T. Hemorrhagic dilation of the fourth ventricle: An ominous predictor. J Neurosurg 1994;80:805-9.

21. Donauer E, Reif J, al-Khalaf B, Mengedoht EF, Faubert C. Intraventricular haemorrhage caused by aneurysms and angiomas. Acta Neurochir (Wien) 1993;122:23-31.

22. Pang D, Sclabassi RJ, Horton JA. Lysis of intraventricular blood clot with urokinase in a canine model: Part 3, Effects of intraventricular urokinase on clot lysis and posthemorrhagic hydrocephalus. Neurosurgery 1986;19:553-72.
23. Lodhia KR, Shakui P, Keep RF. Hydrocephalus in a rat model of intraventricular hemorrhage. Acta Neurochir(suppl) 2006;96:207-11.

24. Yamamoto Y, Waga S. Persistent intraventricular hematoma following ruptured aneurysm. Surg Neurol 1982;17:301-3.

25. Lee KR, Kawai N, Kim S, Sagher O, Hoff JT. Mechanisms of edema formation after intracerebral hemorrhage: Effects of thrombin on cerebral blood flow, blood-brain barrier permeability, and cell survival in a rat model. J Neurosurg 1997;86:272-8.

26. Del Bigio MR, Bruni JE. Changes in periventricular vasculature of rabbit brain following induction of hydrocephalus and after shunting. J Neurosurg 1988;69:115-20.

27. Yanaka K, Hyodo A, Tsuchida Y, Yoshii Y, Nose T. Symptomatic cerebral vasospasm after intraventricular hemorrhage from ruptured arteriovenous malformation. Surg Neurol 1992;38:63-7.

28. Gerard E, Frontera JA, Wright CB. Vasospasm and cerebral infarction following isolated intraventricular hemorrhage. Neurocrit Care 2007;7:257-9.

29. Dull C, Torbey MT. Cerebral vasospasm associated with intraventricular hemorrhage. Neurocrit Care 2005;3:150-2.

30. Kobayashi M, Takayama H, Mihara B, Kawase T. Severe vasospasm caused by repeated intraventricular haemorrhage from small arteriovenous malformation. Acta Neurochir (Wien) 2002;144: $405-6$.

Accepted on 14-02-2009

Source of Support: Nil, Conflict of Interest: None declared.

\section{Author Help: Reference checking facility}

The manuscript system (www.journalonweb.com) allows the authors to check and verify the accuracy and style of references. The tool checks the references with PubMed as per a predefined style. Authors are encouraged to use this facility, before submitting articles to the journal.

- The style as well as bibliographic elements should be $100 \%$ accurate, to help get the references verified from the system. Even a single spelling error or addition of issue number/month of publication will lead to an error when verifying the reference.

- Example of a correct style Sheahan P, O'leary G, Lee G, Fitzgibbon J. Cystic cervical metastases: Incidence and diagnosis using fine needle aspiration biopsy. Otolaryngol Head Neck Surg 2002;127:294-8.

- Only the references from journals indexed in PubMed will be checked.

- Enter each reference in new line, without a serial number.

- $\quad$ Add up to a maximum of 15 references at a time.

- If the reference is correct for its bibliographic elements and punctuations, it will be shown as CORRECT and a link to the correct article in PubMed will be given.

- If any of the bibliographic elements are missing, incorrect or extra (such as issue number), it will be shown as INCORRECT and link to possible articles in PubMed will be given. 